Thorax (1972), 27, 181.

\title{
Oncocytes in human bronchial mucous glands
}

\author{
K. MATSUBA, T. TAKIZAWA, and W. M. THURLBECK \\ Department of Pathology, McGill University, 3775 University Street, Montreal, Quebec, Canada
}

\begin{abstract}
Oncocytes were found in the bronchial glands of 30 of 33 lungs in which the left bronchial tree was examined. They were found with similar frequency in the main, upper and lower lobe bronchi. They were found more commonly with increasing age and were most frequent in the collecting duct of the bronchial glands. However, they were absent from the collecting duct in 14 cases. They were not increased in chronic bronchitics. It is unlikely that bronchial oncocytes have a specific function in bronchial gland ducts but they may represent a curious form of degeneration of epithelial cells as do oncocytes in other organs.
\end{abstract}

Oncocytes, defined by morphological criteria as large epithelial cells with characteristic granular and deeply acidophilic cytoplasm, were first observed by Schaffer in 1897 in the salivary glands of man, but it was not until 1931 that a comprehensive study was made of them (Hamperl, $1931 \mathrm{a}, \mathrm{b})$. They were found in serous and mixed glands of the tongue, pharynx, oesophagus, and trachea (Hamperl, 1931a, 1936). They were not always present in these glands and they were noted with increasing frequency with increasing age of the individual (Hamperl, 1931a). Oncocytes have also been reported in the thyroid, parathyroid, pituitary, adrenal, pancreas, gall bladder, fallopian tubes, and lachrymal glands (Tremblay, 1969). They characteristically stain heavily with oxidative enzymes and, on electron microscopy, large numbers of enlarged mitochondria, sometimes with abnormal morphology, have been seen (Tremblay, 1969). Less is known about the appearance and significance of oncocytes in human bronchial mucous glands. We reported that oncocytes in bronchial mucous glands showed high enzyme activity and did not stain with periodic acid Schiff (Azzopardi and Thurlbeck, 1968). The purpose of this study is to elucidate the appearance and distribution of oncocytes in bronchial glands of human bronchi.

\section{MATERIALS AND METHODS}

We examined the left main bronchus of 33 adult patients from the Autopsy Service of the Pathology Institute, McGill University. They were selected from a series of consecutive random necropsies because adequate $7 \mu$ thick, haematoxylin and eosin stained histological sections were available from three standard sites in the left bronchus (main stem bronchus and main bronchi to the upper and lower lobes).

The oncocytes in the bronchial mucous glands were quantitated as follows: A square graticule, divided into 25 equal squares, was placed in one eyepiece of a binocular microscope and the slides were examined at a magnification of 100 diameters. Mucous glands were divided into three zones-intraglandular zone, ductal zone, and opening zone. The intraglandular zone refers to the gland parenchyma (mucous and serous tubules and adjacent ductal epithelium). The opening zone refers to the area where the bronchial mucous glands open into the bronchial lumen and the duct is lined by ciliated epithelium; the ductal zone refers to the gland duct intermediate between gland parenchyma and the opening zone.

In each zone, each slide was examined using the graticule, and the frequency of oncocytes (oncocytes $\%$ ) was expressed as the percentage of graticule squares containing oncocytes, i.e., the number of graticule squares containing oncocytes divided by the number of squares containing oncocytes plus squares containing glandular, duct or duct opening tissue without oncocytes multiplied by 100 .

The patients' clinical records were reviewed and the patients diagnosed as either having or not having chronic bronchitis, using the Ciba Guest Symposium (1959) criterion of chronic sputum production.

\section{RESULTS}

DIFFERENCE BETWEEN THE SITES The results of the individual cases are shown in Figure 1. The values for the oncocyte \% of the main bronchi showed a range of values from zero to 7.59 with a mean value of 1.78 . The mean values for the upper and lower bronchi were 1.56 and 1.85 respectively, and 


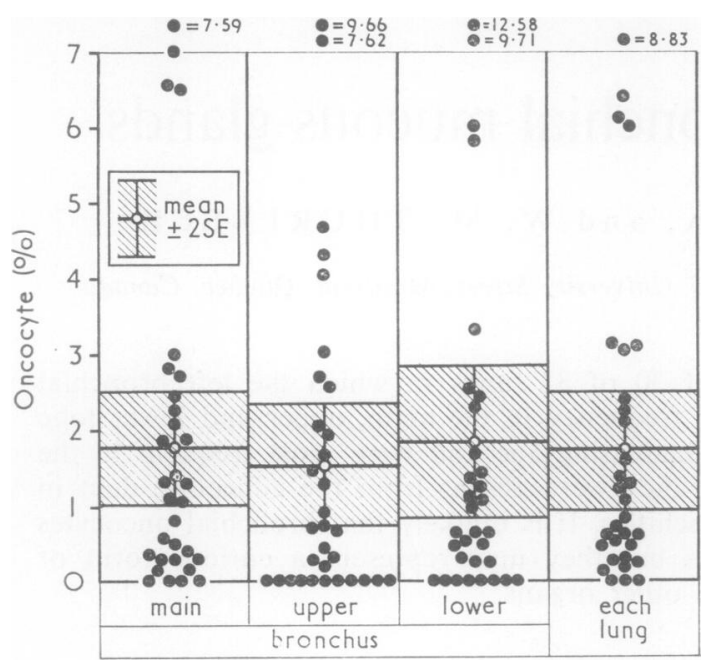

FIG. 1. The percentage of oncocytes is shown in three sites of the left lung-main, upper, and lower lobe bronchus - and as the average of the three sites (each lung). Each closed circle represents one case.

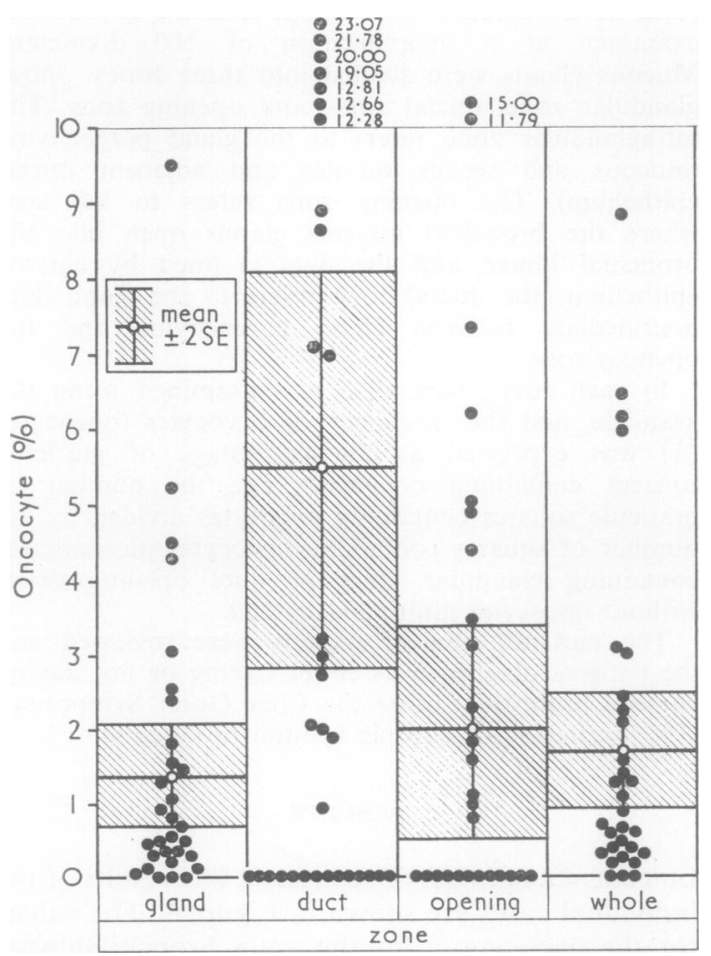

FIG. 2. The percentage of oncocytes in three zones of the tracheobronchial glands is shown as well as the average of the three zones. there were no significant differences between the main and upper bronchi $(t=0 \cdot 40, \mathrm{P}>0 \cdot 1)$, the main and lower bronchi $(t=0 \cdot 11, \mathrm{P}>0 \cdot 1)$, and the upper and lower bronchi $(t=0 \cdot 45, \mathrm{P}>0 \cdot 1)$.

DIFFERENCE BETWEEN THE ZONES (Fig. 2) The values for the oncocyte $\%$ in the intraglandular $\vec{\circ}$ zones were between zero and 9.48 with a mean value of 1.39 . The values in the ductal zones werew between zero and 23.07 with a mean of 5.45 and oncocytes were absent in 14 of 33 cases. Using $x$ the paired $t$ test, the difference between the oncocyte $\%$ in the two zones was significant $(t=3 \cdot 62$, i $\mathrm{P}<0.01)$. The mean value for the opening zonesoo was intermediate to those for the intraglandular $\vec{\circ}$ zones and the ductal zones, and by paired $t$ test $^{-}$ the difference between the opening and ductal $\vec{Z}$ zones was significant $(t=3 \cdot 12, \mathrm{P}<0 \cdot 01)$, whereaso the difference between the opening and intra-⿳亠口冋丁 glandular zones was not significant $(t=0.81$, $\mathrm{P}>0 \cdot 1)$.

RELATIONSHIP WITH AGE There was a significant positive correlation between the oncocyte $\%$ ins each case and age $\left(r=+0.52, P<0.01\right.$, the regres- $\frac{}{0}$ sion equation being $\mathrm{Y}=2 \cdot 2955+0 \cdot 0684 \mathrm{X})$.

RELATIONSHIP WITH BRONCHITIS There were nine chronic bronchitics and 24 non-chronic bronchiticso in this study. The mean values for the oncocyte $\%$ in chronic bronchitics and non-chronic bronchitics were 1.66 and 1.76 respectively. There was no significant difference between these two groups $(t=0 \cdot 11, \mathrm{P}>0 \cdot 1)$.

\section{DISCUSSION}

We have examined the frequency of oncocytes in bronchial mucous glands in three standard sites ino the left lung of 33 cases. Oncocytes were found in 30 of the 33 cases, the exceptions being patientso under the age of 30 years, and oncocytes were found with increasing frequency with increasing age. They were found with similar frequency in $N$ mainstem, upper, and lower lobe bronchi and N were not found more frequently in chronico bronchitics. Oncocytes were found more often in the ducts of the bronchial glands than at otherc sites, but their frequency was very variable: theres? were no oncocytes in 14 cases and there were $10 \%$ or more in 7 of 33 cases.

Meyrick, Sturgess, and Reid (1969) recon $\stackrel{\mathbb{\Omega}}{\Omega}$ structed the duct system and secretory tubules of a bronchial submucosal gland in a human main bronchus and reported that the duct system was divided into two parts-ciliated duct and collect? 


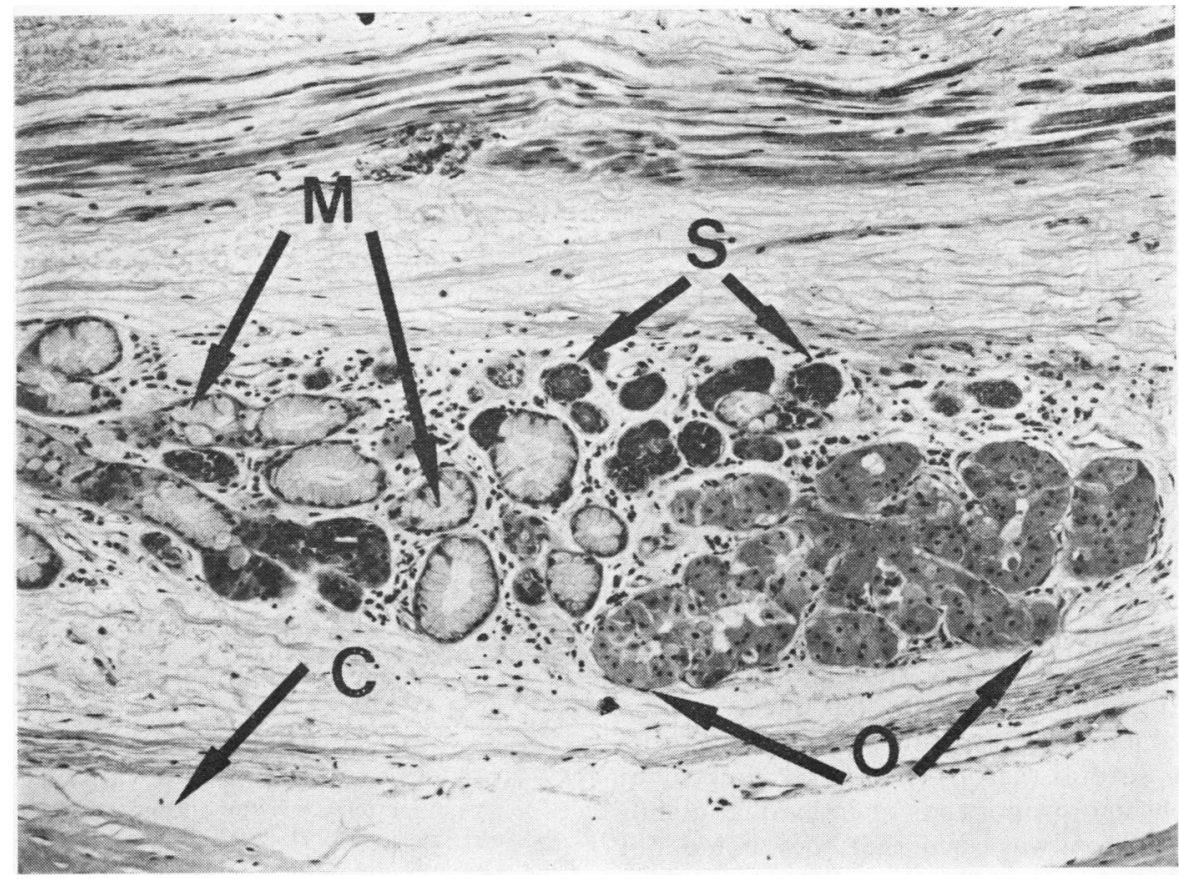

FIG. 3. The peripheral quarter of a mucous gland consists entirely of oncocytes $(O)$. Mucous tubules $(M)$ and serous tubules $(S)$ can easily be seen. Bronchial cartilage is marked ' $C$ '. Haematoxylin and eosin $\times 100$.

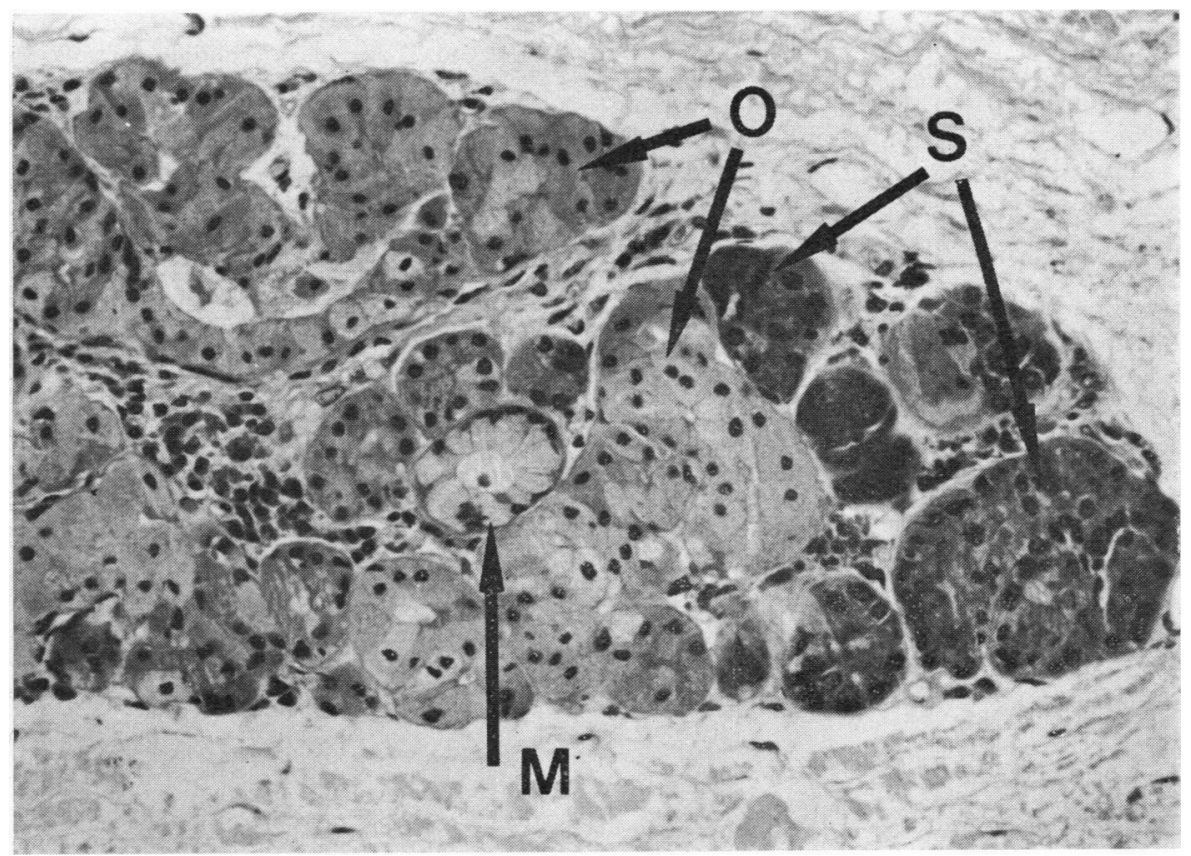

FIG. 4. Another mucous gland is shown at higher magnification. The greater proportion of the gland is formed by oncocytes. Mucous and serous tubules are clearly visible. Haematoxylin and eosin $\times 250$. Abbreviations as in Fig. 3 . 
ing duct. The epithelial cells of the collecting duct had the appearance of oncocytes by both light and electron microscopy. They made the interesting suggestion that oncocytes might have a special function controlling ionic and water concentration of the gland secretion.

Our study shows that oncocytes were present in intraglandular, ductal, and opening zones and were not confined to the ducts. In more than onethird of the cases, the ducts did not contain oncocytes. Our observations can be justly criticized because they are based on single sections rather than on serial section reconstructions. The absence of oncocytes in the collecting ducts indicates that at least part of these ducts is not normally lined by oncocytes. The presence of oncocytes in the intraglandular zone could be interpreted as representing oblique sections of oncocytes forming the walls of ducts in the glandular zones. However, this was unlikely to be the case for several reasons. Frequently oncocytes formed such high proportions of individual glands and their position was such that they could not represent ductal cells only (Figs 3 and 4). Also the variation in the proportion of oncocytes was so great from patient to patient (see Fig. 2) that it is unlikely that they could represent a normal component of the gland.

Finally, the frequency of oncocytes was age related, as is the frequency of oncocytes in salivary glands (Hamperl, 1931a), suggesting that they are not normal cells but degenerate cells. It is also true that oncocytes of the bronchial mucous glands show the same heavy staining for oxidative enzymes as do oncocytes of parathyroid, thyroid, and salivary glands (Tremblay, 1969). Thus it seems more likely that the oncocytes of the bronchial mucous glands are similar to the oncocytes in other organs rather than being a different cell with a specific function. We do not wish to imply that ductal cells may not have a secretory or absorptive function as suggested by Meyrick et al. (1969). Indeed, since oncocytes are usually found in secretory epithelial tissue and likely represent altered cells, this suggests a secretory function for the ductal epithelium. We merely imply that the oncocytes in the bronchial glands are unlikely to have a specific function.

We can add no further information concerning $\frac{\widehat{D}}{\vec{\sigma}}$ the nature of the oncocyte. It is commonly $\varrho$ believed that oncocytes represent a peculiar form $\%$ of degeneration of epithelial cells (Hamperl, 1950, $\vec{\circ}$ 1962) and that they have diminished secretory activity despite apparent increased metabolic $\vec{\omega}$ activity (Tremblay, 1969) and our findings are consistent with this hypothesis. We agree with $\vec{x}$ Meyrick et al. (1969) that the term 'oncocyte' is $v$ an unfortunate one as it may be thought to imply i neoplastic change, but it is a word in current usage $\vec{\infty}$ and no satisfactory alternative is available.

This study was supported by the Medical Research Council of Canada.

\section{REFERENCES}

Azzopardi, A., and Thurlbeck, W. M. (1968). Oxidative enzyme pattern of the bronchial mucous glands. ? Amer. Rev. resp. Dis., 97, 1038.

Ciba Guest Symposium (1959). Terminology, definitions, 은 and classification of chronic pulmonary emphysema and related conditions. Thorax, 14, 286.

Hamperl, H. (1931a). Onkocyten und Geschwülste der Speicheldrüsen. Virchows Arch. path. Anat., 282, 724. ®

,$-(1931 b)$. Beiträge zur normalen und pathologischen $\vec{F}$ Histologie menschlicher-Speicheldrüsen. $Z$. mikr.-윽 anat. Forsch., 27, 1.

- (1936). Über das Vorkommen von Onkocyten in verschiedenen Organen und ihren Geschwülsten. Virchows Arch. path. Anat., 298, 327.

_, (1950). Onkocytes and the so-called Hürthle cello tumor. Arch. Path., 49, 563.

- (1962). Benign and malignant oncocytoma. Cancer (Philad.), 15, 1019.

Meyrick, B., Sturgess, J. M., and Reid, L. (1969). A recon-ī struction of the duct system and secretory tubules of $\mathrm{O}$ the human bronchial submucosal gland. Thorax, 24, 729.

Schaffer, J. (1897). Beiträge zur Histologie menschlicher윽 Organe, IV-VII. S. B. Kais. Akad. Wiss. (Wien) Math. Nat.-Classe, Abt. 3, 106, 353.

Tremblay, G. (1969). The oncocytes. In Methods and Achievements in Experimental Pathology, Vol. 4. N Examples of Descriptive and Functional Morphology, edited by E. Bajusz and G. Jasmin, p. 121. Karger, $O$ Basel. 